\title{
BMJ Open Exploring community perceptions, attitudes and practices regarding the COVID-19 pandemic in Karachi, Pakistan
}

\author{
Anam Shahil Feroz (D , ${ }^{1,2}$ Naureen Akber Ali, ${ }^{1}$ Ridah Feroz, ${ }^{3}$ Noshaba Akber, ${ }^{1}$ \\ Salima Nazim Meghani ${ }^{1}$
}

To cite: Shahil Feroz A,

Ali NA, Feroz R, et al.

Exploring community perceptions, attitudes and practices regarding the COVID-19 pandemic in Karachi, Pakistan. BMJ Open 2021;11:e048359. doi:10.1136/ bmjopen-2020-048359

- Prepublication history and additional supplemental material for this paper are available online. To view these files, please visit the journal online. (http://dx.doi.org/10.1136/ bmjopen-2020-048359).

ASF, NAA and RF are joint first authors.

Received 05 January 2021 Accepted 29 July 2021

\section{Check for updates}

(C) Author(s) (or their employer(s)) 2021. Re-use permitted under CC BY-NC. No commercial re-use. See rights and permissions. Published by BMJ.

${ }^{1}$ Community Health Sciences Department, Aga Khan University, Karachi, Pakistan ${ }^{2}$ Dalla Lana School of Public Health, Institute of Health Policy Management and Evaluation, University of Toronto, Toronto, Ontario, Canada

${ }^{3}$ Institute for Educational Development, Aga Khan University, Karachi, Pakistan

Correspondence to Ms Anam Shahil Feroz; anam.shahil@mail.utoronto.ca

\section{ABSTRACT}

Background The Government of Pakistan is facing difficulty to contain the surge of COVID-19 due to the country's social, political, economical and cultural context. Experiences from the previous epidemic suggest that community perceptions, social norms and cultural practices can impede COVID-19 containment. To understand social responses towards COVID-19, the study aims to explore the understanding of COVID-19 and the acceptance of control measures among community members.

Methods We conducted an exploratory qualitative study using a purposive sampling approach, at two communities of Karachi, Pakistan. In-depth interviews were conducted with community members including, young, middleaged and older adults of both genders. Study data were analysed manually using the conventional content analysis technique.

Results A total of 27 in-depth virtual interviews were conducted, between May and June 2020. Six overarching themes were identified: (1) community knowledge and perceptions around COVID-19; (2) trusted and preferred sources of health information; (3) initial thoughts and feeling towards COVID-19 pandemic; (4) community practices to prevent exposure from COVID-19; (5) perceived risks associated with poor adherence to infection control practices; and (6) future preparedness of community to avoid the second wave of the outbreak. Generally, community members had good knowledge about COVID-19, and positive behaviour and attitude towards using standard precautions. The knowledge is mainly acquired through electronic, print and social media platforms, which have pros and cons. However, some community members including younger individuals had poor adherence to safety measures. This may necessitate concentrated efforts to raise awareness through community mobilisation and sensitisation activities.

Conclusion This study provides an initial evidence base of communities' perceptions, and attitudes towards COVID-19 in an early stage of pandemic. The study emphasises that sufficient knowledge and awareness about COVID-19, adequate training and drills, and adherence to safety measures, are necessary to better prepare for the second wave of COVID-19.

\section{STRENGTHS AND LIMITATIONS OF THIS STUDY \\ $\Rightarrow$ This study provides an initial evidence base of communities' perceptions, and attitudes towards COVID-19 in an early stage of the pandemic when the communities just start to learn about the COVID-19 virus. \\ $\Rightarrow$ The use of conventional content analysis helped un- derstand in-depth views of communities' perspec- tives and attitudes towards the COVID-19 pandemic. \\ $\Rightarrow$ The study invited participants from two communities of Karachi; therefore, our data might have missed views, from other major ethnic and cultural groups. \\ $\Rightarrow$ One limitation is that to minimise the risk of infec- tion all study respondents were interviewed online over Zoom and hence, the authors did not have the opportunity to build rapport with the respondents or obtain non-verbal cues during interviews.}

\section{BACKGROUND}

By 29 June 2020, the failure to control the COVID-19 outbreak had resulted in 182277 425 COVID-19 cases and 3947643 deaths worldwide. ${ }^{1}$ As of 29 July 2021, Pakistan has recorded more than 956392 COVID-19 cases with 22254 deaths. $^{2}$ On 26 February 2020, the first case of COVID-19 was reported from Karachi. ${ }^{3}$ The cases increased exponentially since the lockdown was lifted in late May and June, 2020. ${ }^{4}$ The uptick in cases was perhaps due to the Eid festival which happened in late May 2020. Many awareness campaigns were initiated for the general population by both local and federal governments in Pakistan to spread awareness about the risks, signs and symptoms of COVID-19. One of the campaigns involved spreading awareness to the masses through text messages, which were sent by the government of Pakistan on all mobile networks. In addition, recorded voice messages in various local languages including Urdu, Pashto and Sindhi were used as caller tunes before every phone call to warn against 
the risks of COVID-19, its spread, and complications to help control the COVID-19 spread. ${ }^{5}$

The Government of Pakistan has been facing difficulty to contain the surge of COVID-19 due to the country's social, political, economical and cultural context. The increased resistance by communities and local and religious leaders has made it even more challenging to slow down the spread of COVID-19. ${ }^{6}$ There have been many generalised and subjective explanations of community interactions with COVID-19 and its control activities. In Pakistan, the initial response of the communities to the rising threat of COVID-19 was that of a generally reported apathy and indifference. ${ }^{7}$ Despite several public health messages by health ministry, ${ }^{8}$ communities are not adhering to the infection control precautions which are regularly reinforced through mainstream media. The non-cooperative attitude displayed by the public has further fuelled the rapid transmission of the disease across the country. ${ }^{9}$ Community practices, and attitudes towards COVID-19 have been described as barriers to an effective response. ${ }^{10}$ Experiences from the previous epidemic suggest that community perceptions, social norms and cultural practices can impede the containment of COVID-19. ${ }^{11}$ The fight against Ebola in Africa was subjected to similar challenges. ${ }^{12}$

A large body of evidence supports the value of qualitative methods in epidemic and pandemic research. Leading global health agencies like the WHO and the Centers for Disease Control and Prevention (CDC) recommend using qualitative methods in epidemiological investigations to capture social responses to the pandemic. ${ }^{13}$ So far various quantitative studies have been conducted on COVID-19 to study the epidemiology of the disease. However, these studies are not well suited to capture the social implications of disease including the reasons for individuals' behaviour, the social connections or the ways families make sense of what is happening around them. Qualitative lessons from recent epidemics like severe acute respiratory syndrome, H1N1 and Ebola virus disease $^{11}$ highlight how to engage with the social, cultural and political facets of the epidemic to build effective interventions. ${ }^{13}$

To understand social responses towards COVID-19, it is important to explore the understanding of COVID-19 and the acceptance of control measures among the community. Given the significance of qualitative inquiry, the current situation in Karachi, Pakistan demands an exploration of community perceptions, attitudes, practices regarding the COVID-19 pandemic. The open-ended nature of the study will help focus on how individuals and communities perceive COVID-19 disease.

\section{METHODS}

\section{Study design and setting}

This study used an exploratory qualitative research design using a purposive sampling approach. The study was conducted in two muslim communities of Karachi city. These include Karimabad Federal B Area Block 3 Gulberg Town, and Garden East and Garden West area of Karachi city.

Karimabad is a neighbourhood in the Karachi Central district of Karachi, Pakistan. It is situated in the south of Gulberg Town bordering Liaquatabad, Gharibabad and Federal B. Area. The population of this neighbourhood is predominantly Ismailis. People living here belong mostly to the middle class to the lower middle class. It is also known for its wholesale market for sports goods and stationery. Garden is an upmarket neighbourhood, which is in the Karachi South district of Karachi, Pakistan. It is subdivided into two neighbourhoods: Garden East and Garden West. It is the residential area around the Karachi Zoological Gardens; hence, it is popularly known as the 'Garden' area. The population of Garden used to be primarily Ismaili and Goan Catholic but has seen increasing numbers of Memons, Pashtuns and Baloch. These areas have been selected purposively to interview members of these communities.

This design did not intend to look at the differences between the two neighbourhoods with regard to perceptions and attitudes towards COVID-19 but rather to understand how community members in Karachi, Pakistan perceive COVID-19 disease and its precautionary measures.

\section{Data collection methods and study participants}

The data collection methods included in-depth interviews (IDIs) with community members. The IDIs aimed to explore community perceptions, attitudes, practices regarding the COVID-19 pandemic in Karachi, Pakistan. Adult community members of different ages and both genders who have not contracted the COVID-19 disease were purposively recruited from both sites, as mentioned in below table 1 .

Since this study aimed to explore general community perceptions, attitudes, practices regarding the COVID-19 pandemic, participants were excluded if they or their family members have been tested positive for COVID-19

Table 1 Study participants for in-depth interviews (IDIs)

\begin{tabular}{lcl}
\hline In-depth interview participants & Total IDIs=27 & Male=13; Female=14 \\
\hline Young adults (18-35 years) & 12 & Male=6; Female=6 \\
\hline Middle-aged adults (36-55 years) & 8 & Male=4; Female=4 \\
\hline Older adults ( $>55$ years) & 7 & Male=3; Female=4
\end{tabular}


or have been isolated/quarantined because of recent exposure. Because COVID-19 survivors and their family members might have different perceptions compared with the general community.

\section{Data collection procedure}

A semi-structured interview guide was developed for conducting IDIs (online supplemental file 1). The interview guide included questions on sociodemographic characteristics, community knowledge, perceptions, and attitudes towards COVID-19, community practices to prevent exposure from COVID-19, perceived risks associated with poor adherence to safety measures, and perceptions on future preparedness for the second wave of COVID-19. The interview guides were pilot tested with a non-study sample (2 IDIs) with the same characteristics as the study sample. The pilot testing offered evidence-based guidance to improve data collection guides.

The IDI participants were identified and contacted via the pre-existing community WhatsApp and email groups. The researchers obtained access to these groups through community leaders of both neighbourhoods. The community leaders, gatekeepers in this study, supported the identification of a purposive sample through both communities. A total of 35 eligible individuals were contacted through these groups, out of which 27 agreed to participate in the study. Interviews were scheduled for participants' convenient day and time. Before beginning the interview, the study investigators explained the study objectives and procedures to eligible community members and obtained informed consent for their participation in the study. Informed consent was also obtained on either email or WhatsApp, for notetaking and audio recording of the interviews. Participants who were unable to write their names were asked to provide a thumbprint on the consent form to symbolise their consent to participate. Trained researchers, experienced in qualitative research, conducted online interviews via Zoom or Skype. At the start of the interview, each participant was asked to provide sociodemographic details including age, gender, educational level and occupation. The interviews were conducted in the languages of English and/or Urdu. Each interview took around 30-40 min in duration. Study participants were assured that their information will remain confidential, and no identifying features will be mentioned on the transcript.

Data collection was ceased once saturation was achieved; saturation refers to the point in the research process when no new information is discovered in data analysis. ${ }^{14}$ The sample size was not predetermined, and an iterative approach of simultaneous data collection and analysis was taken to determine the point of data saturation. Data saturation refers to the point in the research process when no new information is discovered in data analysis and this redundancy signals to researchers that data collection may cease. ${ }^{15}$

\section{Data analysis}

Study data were analysed manually using the conventional content analysis technique. ${ }^{16}$ First, the audio recordings from the interviews were transcribed and then translated into the English language. No identifying characteristics were included in the transcriptions. Transcripts were read several times by research investigators to develop an interpretation of the community perceptions, attitudes, practices regarding the COVID-19 pandemic. This involved an iterative process where data were coded, compared, contrasted and refined to generate emergent themes by two independent investigators. The transcribed text was divided into 'meaning units' which were later shortened and labelled with a 'code' without losing the study context. Codes were then analysed and grouped into similar categories. In the final step, similar categories were assembled under subthemes and main themes.

\section{Patient and public involvement}

Patient public involvement is a relatively new concept in Pakistan. Our data collection tool was piloted through two IDIs to ensure that it is inclusive and comprehensive. We will also engage them in disseminating the findings of this study, particularly their contribution while developing research briefs in plain language and communicating them to community members will be very valuable.

\section{RESULTS}

In this qualitative study, 27 IDIs were conducted, between May and June 2020, with a variety of community members including, young adults, middle-aged adults and older adults of both genders. The characteristics of study participants are presented in table 2. None of the study participants belonged to the same family. All study participants were Muslim belonged to low-middle class families. Based on the data collection and conventional content analysis, six overarching themes were identified (1) community knowledge and perceptions around COVID19; (2) trusted and preferred sources of health information; (3) initial thoughts and feeling towards COVID-19 pandemic; (4) community practices to prevent exposure from COVID-19; (5) perceived risks associated with poor adherence to infection control practices; and (6) future preparedness of community to avoid the second wave of outbreak. The themes are presented below with illustrative quotes.

\section{Themes}

Community knowledge and perceptions around COVID-19

Mixed responses were received for the question on community members' knowledge on COVID-19. Community members shared that initially they had no knowledge about COVID-19 but with time they were able to acquire fairly good knowledge about this virus in general and its signs and symptoms, since it was first identified in Wuhan, China. Highlighting this point, one respondent stated: 
Table 2 Characteristics of in-depth interview (IDI) study participants (IDIs=27)

\begin{tabular}{llcc} 
Characteristics of IDI participants & & N (\%) or mean \pm SD & Median (range) \\
\hline Gender & Female & $14(51.9 \%)$ \\
Age & Male & $13(48.1 \%)$ \\
Educational Level & & $39.62 \pm 13.94$ & $36(21-64)$ \\
& Intermediate & $5(18.5 \%)$ \\
\hline Occupation & Bachelors & $13(48.1 \%)$ \\
& Masters & $9(33.3 \%)$ \\
& Homemaker & $6(22.2 \%)$ \\
& Students & $2(7.4 \%)$ \\
& Working professionals & $19(70.4 \%)$
\end{tabular}

I did not know much about it earlier but whatever right information is served on social media I am aware of it. I know things like what it is? how it is spreading out? and how to take care of my family? Though I am not getting much into the scientific part of it. (IDI-02, Female)

Participants stated that they are updating their knowledge continuously through certificate courses, journal publications, news, social media and so on.

I believe I have fairly good knowledge of this virus as I have recently completed two online certificates on the COVID-19 pandemic. (IDI-17, Male)

A few community members verbalised that initially, they were so curious to know about COVID-19 but now they have been avoiding reading about it because it causes a lot of anxiety and stress. Commenting on the negative consequences of too much information, one female community member stated:

I am not curious to know more about this virus because the deluge of information can make me feel overwhelmed and cause anxiety and depression disorder. I am only following basic prevention tips to prevent my exposure to COVID-19. (IDI-11, Female.)

\section{Trusted and preferred sources of health information}

When asked about their understanding of trusted sources of information, participants listed several trusted sources including, news channels, information from government authorities, webinar sessions by different hospitals, information from community-based groups, WHO website, updates from relatives and friends working in the medical field, electronic media, research journals and so on.

I think that there are many sources that provide reliable information about COVID-19. These include print media, social media, news channels (BBC/ CNN), government authorities, webinar sessions by aga khan university hospital (AKUH), etc. (IDI-06, Female.)
However, a few community members raised concerns about the authenticity of the information available on electronic and social media such as Facebook, WhatsApp and so on. This point was illustrated by a respondent who stated:

We are not relying much on the news channels because we think that the media does not present a true picture of the current situation. Sometimes, the news channels exaggerate the news so much and create negativity in our minds. (IDI-04, Female)

Some community members mentioned that they prefer to gain information from close friends and relatives who are working in hospitals and are directly involved in the care of patients with COVID-19. Others mentioned that their preferred information sources include social media (WhatsApp groups, Instagram), news channels, mainstream media, guidelines from community-based institutions and religious institutions, Aga Khan University hospital sessions and self-study research through WHO and CDC websites and so on.

I have an advantage because I have a person in my family who is from the medical field so I can get updated knowledge at all times. Also, from the very beginning, I am following the WHO page, AKUH webinars, and news channels like BBC and CNN. I rarely refer to the local site because I think the information there is also not reliable. (IDI-07, Female)

Expressing similar concerns, a female community member stated:

I would rather prefer to rely on information circulated by religious institutions because that provides authentic, concise, and relevant evidence on COVID-19. (IDI-06, Female)

Initial thoughts and feelings towards COVID-19 pandemic The research participants described initial thoughts and feeling towards the COVID-19 pandemic. Most community members perceived a sense of shock and chaos in the initial days because all were quickly shut down from 
schools, public places, markets to religious places. Further participants expressed the feeling of confusion, depression and anxiety.

To be very honest, I was very petrified with this idea especially looking at the situation in china. I was also supposed to travel but I canceled the tickets because I did not want to be stuck in another country. I was very much taking it into my head. Until now, I would not say I have become completely indifferent, but I am a little relaxed than before. (IDI-07, Female)

On the other hand, few participants mentioned that the initial days were fun as many of them got the opportunity to unwind themselves from busy routines, but after a couple of days, the change felt drastic, shocking and difficult to contain.

Initially, it felt like any other disease outbreak like influenza, malaria, HIV ... honestly, I felt a sense of relief ... we were discussing in our family that it's good that we are getting enough time for fun and relaxation. But when the strict lockdown was announced, it was hard to face the reality of the COVID-19 pandemic. (IDI-05, Female)

A few community members indicated that they were initially confused about the overall situation and were trying to figure out whether COVID-19 is a hype or a real danger. The participants verbalised that it took some time to internalise the new normal as it filtered down to them.

Initially I felt like this is all fake and exaggerated. I told my son that people have created hype on it. But when religious institutions got closed for ensuring social distancing ... then I realized that this is something really dangerous. (IDI-22, Female)

\section{Community practices to prevent exposure from COVID-19}

Several preventive strategies were mentioned by community members to prevent exposure to COVID-19. These include social distancing, staying at home, hand washing, use of alcohol-based hand rubs, steam inhalation and frequent use of the antiseptic spray for disinfection purposes. Many community members mentioned that they make Dettol spray for disinfecting utensils, door handles and other miscellaneous items that are purchased from markets on a routine basis. Also, participants verbalised that they wear masks and gloves if they plan to go outside for groceries or any other necessary task. On return, they wash their hands, take shower and disinfect all their stuff to prevent exposure to infection.

We are wearing masks and sanitizing all the time when we go out of the home. I usually avoid going out, but when I go, I plan my day in a way that I get done with most of the tasks. Just today, I went out for one hour to draw cash from the bank, and purchase groceries. (IDI-09, Male)
A few community members stated that they have allocated separate rooms and utensils for family members who are working in a hospital setting.

My sister is a doctor... we used to share a room before but now in the time of COVID-19 we have allocated a separate room to her. When she gets back from the hospital, we disinfect her first using Dettol spray, and then she takes a shower. She wears a mask all the time when she is at home. (IDI-07, Female)

Perceived risks associated with poor adherence to infection control practices

Most respondents reported that there will be an increase in the number of COVID-19 cases as a result of poor adherence to infection control practices. In particular, community members notified that the younger generation may inflict damage in the community due to their poor adherence to precautionary measures.

If I stand in my balcony, I see that there are a lot of people socializing in the colony and are not wearing a mask. The young generation is standing in groups and is interacting ... not maintaining social distancing. They are going back to their homes and risking the lives of elders and children in their families. (IDI09, Male)

Besides, participants highlighted that during the Eid festival, individuals were observed not to follow standard precautions which may result in huge losses. A few participants stated that each member of the community should ensure their social responsibility by wearing a mask, maintaining social distancing and following other standard operating measures (SOPs) set by community leaders.

As Eid is coming, people are visiting markets for purchasing stuff as if nothing has changed. There is so much traffic in the shopping area... no SOPs are being followed. People are not playing their part when it comes to social responsibility. I presume that there will be so much damage to the communities ... if people would not follow safety precautions. (IDI03, Female)

Future preparedness of community to avoid the second wave of the outbreak

When asked about community preparedness to prevent the second wave of outbreak, several participants suggested that drills and training should be organised for communities to ensure better preparedness.

I believe that as soon as this situation resolves... the community should focus on drills and training for the second wave of COVID-19 or any other outbreak in the future. The drills and training can include things like what mode of communication should the community prefer when staying at home? What sources to rely on? etc. The drills should be performed on 
a routine basis as we do for earthquakes and other natural disasters. (IDI-20, Male)

Also, members of the community recommended that the role of community nursing, basic health units, and community health centres should be recognised to adequately respond to the second wave of COVID-19. Alongside this, community members suggested that the government should ensure strict compliance to SOPs through regulatory reforms. Finally, members recommended that the community should do fundraising activities to ensure fund allocation for underserved individuals.

There is a great role of community sciences because awareness about prevention can be created from that ground ... also fund-raising activities should be encouraged in communities to help poor people during the second wave of COVID-19. (IDI-15, Female)

\section{DISCUSSION}

To the best of our knowledge, this is the first study to explore community perceptions, attitudes, practices regarding the COVID-19 pandemic in Karachi, Pakistan. The study investigated initial thoughts and feelings of the community towards COVID-19, community knowledge around COVID-19, trusted sources of information and preferred communication channels, current community practices to prevent exposure, perceived risks associated with poor adherence to safety measures and future preparedness of the community to avoid second COVID-19 wave.

In general, study participants in our research had a fairly good level of knowledge about COVID-19, its spread and prevention techniques. Our study participants acquired knowledge about disease via several sources including, certificate courses, journal publications, news and social media. These findings are generally consistent with the results of the study conducted on Egyptian adults, in which participants gained a good general knowledge of the disease, its methods of spread and prevention via several novel channels including, social media platforms. ${ }^{17}$ Concurrently, a few members of the community showed reluctance to obtain new knowledge as it tends to generate anxiety and stress among them. The reluctance among community members was also apparent in a study conducted with the Indian population, where nearly half the participants felt panic after reading reports of the COVID-19 pandemic on the electronic and print media over the past week. ${ }^{18}$

When we asked participants about trusted and preferred sources of information to learn about COVID19, participants listed several trusted sources including electronic media, print media, mainstream media, social media and so on. The preferred sources of information also indicated internet literacy in the community members, to some extent. Another interesting and unique finding is that participants preferred receiving information from religious institutions and relatives and friends working in hospital facilities. Participants also indicated that although these sources provide a simple and accessible way of being informed, they can also be a cause of misinformation. Abdelhafiz et al study reported one such example of misinformation, where Facebook disseminated fake news about the drug, hydroxychloroquine and its potential to treat patients with COVID-19. This fake information encouraged a lot of individuals to keep stock of this drug, leading to a shortage of this medicine. ${ }^{17}$ Thus, these sources of information should be used with caution, to avoid the spread of fabricated data, rumours and unauthentic information. ${ }^{17}$ Future research is needed to study the impact of the misinformation that is received from religious institutions, relatives and friends working in hospital facilities.

In our study, most participants perceived a sense of shock and chaos in the initial days of the pandemic because of the lockdown and closure of all routine activities. Participants expressed a feeling of confusion, depression and anxiety as a result of unexpected turmoil. Similar thoughts and emotions have been reported by many others in COVID-19 studies conducted in China, where participants perceived COVID-19 as a life-threatening danger. ${ }^{19} 20$ Alternatively, few participants enjoyed the initial lockdown days as it provided them an opportunity to reset their lives. Interestingly, a few community members believed that media has created artificial hype or hysteria around the new virus for some potential gain. This finding is interesting as it reflects the growing awareness of the community regarding COVID-19 and highlights the cons of using social media platforms as a trusted source of information. The outbreak of the Swine influenza also linked the virus with media hype. ${ }^{21}$ The COVID-19 pandemic has already seen a rise in conspiracy theories, fake news and misinformation. Therefore, it is hard for communities to distinguish scientific evidence and facts from less reliable sources of information. ${ }^{22}$ The Nature Medicine article clarified that the virus is not purposefully manipulated or created in laboratories. ${ }^{23}$ Our study found that participants needed adequate time to internalise the new normal as it filtered down to them. Thus, a systemic resilience approach is essential to deal with a sense of shock and drastic change associated with the COVID-19 pandemic. $^{22}$

Our results undoubtedly show that participants have a positive general attitude towards safety measures to prevent the transmission of the COVID-19 virus. Participants believed in the value of maintaining social distancing, staying at home, cleaning hands with soap water or alcohol-based sanitizer, wearing a facemask and using Dettol disinfectant spray. It has also been seen in another COVID-19 study that community members are adhering to safety precautions to avoid virus transmission. This indicates the positive behaviour and attitude of the community towards COVID-19, as a result of better community sensitisation. ${ }^{18}$ A unique yet encouraging finding reported by our study was that the community 
members allocated separate rooms and utensils for family members who are working in a hospital setting. This indicates that most participants in our study had adequate awareness of safety measures for preventing exposure to COVID-19.

Commenting on the perceived risk associated with the COVID-19 outbreak, the majority of the participants in this study expressed a high level of susceptibility in contracting COVID-19 as a result of poor adherence to safety measures by some community members. Our study participants notified that the younger generation may inflict damage in the community as safety precautions are not being followed. WHO also confirms that the younger generation is driving COVID-19 spread because symptoms are often milder or none at all in the young people, and many are unaware that they are infected and unknowingly passing on the virus to others. ${ }^{24}$ This finding indicates that community mobilisation and sensitisation activities are still weak and require concentrated efforts to raise awareness and resolve misconceptions that are associated with an increase in COVID-19 cases. In such circumstances, it is recommended that community leadership should set rules and regulations to help individuals avoid behaviours that are no longer considered socially responsible. $^{22}$

Finally, community members recommended ongoing training and drills to prevent the second wave of the COVID-19 outbreak. A viewpoint by Dzigbede et al reported that local governments should implement disaster training exercises to prepare for the second wave of COVID-19. ${ }^{25}$ Such training have the potential to strengthen local response and recovery from the COVID-19 pandemic. ${ }^{25}$ One encouraging finding of the study was that the members of the community recognised that the role of community nursing, and community health centres to prepare for the second wave of COVID19. This has also been emphasised by Bavel et al in a perspective paper. Since the COVID-19 crisis requires large-scale behaviour change, the role of community health sciences and social and behavioural sciences is of utmost value to help align human behaviours with the recommendations of epidemiologists and public health experts. $^{22}$

Since the study was conducted in the month of May and June 2020, it provides an initial evidence base of communities' perceptions, and attitudes towards COVID-19 in an early stage of the pandemic when the communities just start to learn about the COVID-19 virus. The study data collection period observed an uptick in the daily new COVID-19 cases as well as total deaths perhaps due to the Eid festival. ${ }^{26}$ The uptick in the cases might have influenced the community perceptions and attitudes towards COVID-19 and community members might have taken stringent measures to prevent exposure during the surge. The community perceptions and attitudes towards COVID-19 and its precautionary measures may be different at the present time given that the community has acquainted with the current situation. One of the limitations of this study was that all study respondents were interviewed online, to minimise the risk of infection. In online interviews, the authors did not have the opportunity to build rapport with community members over Zoom or obtain non-verbal cues during interviews. Second, due to the nature of outbreak prevention, the study was unable to conduct focus group discussions with community members, which would have provided detailed information about personal and group feelings. Besides, the timings of interviews (May-June 2020) is also one of the limitations of this study as the results would have yielded a different picture if participants would have been interviewed in Feb and March 2020, when the pandemic just occurred in Pakistan. Lastly, this was a short-term study and does not involve long-term perceptions of the community members with this pandemic.

The findings from this study will help tailor existing public health interventions to address the social and behavioural problems related to this pandemic. The findings from this study can be directly used for improving community preparedness and response for possible future COVID-19 waves or other outbreaks. Future research should be directed at developing and implementing contextual interventions to improve community understanding and social responses towards COVID19. In addition, future research could be conducted to capture any temporal changes in community perceptions and attitudes, especially with respect to vaccinations.

\section{CONCLUSION}

This study provides an in-depth view of communities' perspectives and attitudes towards the COVID-19 pandemic. Generally, community members had good knowledge about COVID-19, and positive behaviour and attitude towards using standard precautions, which is important to prevent exposure to COVID-19. The knowledge is mainly acquired through electronic media, print media and social media platforms, which have pros and cons. However, some community members including younger individuals had poor adherence to safety measures. This may necessitate concentrated efforts to raise awareness and resolve misconceptions through community mobilisation and sensitisation activities. The study emphasises that sufficient knowledge and awareness about COVID-19, adequate training and drills, and adherence to safety measures, are necessary to better prepare for the second wave of COVID-19. Lessons learnt from this study are extremely valuable and can be transferable to community settings in Pakistan that have similar sociodemographic characteristics. However, findings cannot be extrapolated to other countries because of the differences in participant demographics and health system constraints.

Contributors ASF and NAA designed the study and analysed and interpreted the data. All authors collected the data. ASF wrote the first draft of the manuscript. All authors contributed to reviewing and editing the manuscript. 
Funding The authors have not declared a specific grant for this research from any funding agency in the public, commercial or not-for-profit sectors.

Competing interests None declared.

Patient consent for publication Not required.

Ethics approval Ethical approval for this study was obtained from the Aga Khan University Ethical Review Committee (AKU-ERC) - [2020-4825-10599]. Written informed consent was provided by all study participants. Informed consent included permission to audio record the interviews and use anonymised quotes. Voluntary participation and the right to ask any questions and to decline participation at any time were emphasised during the data collection.

Provenance and peer review Not commissioned; externally peer reviewed.

Data availability statement Data are available upon reasonable request. The datasets used and/or analysed during the current study are available from the corresponding author on reasonable request.

Supplemental material This content has been supplied by the author(s). It has not been vetted by BMJ Publishing Group Limited (BMJ) and may not have been peer-reviewed. Any opinions or recommendations discussed are solely those of the author(s) and are not endorsed by BMJ. BMJ disclaims all liability and responsibility arising from any reliance placed on the content. Where the content includes any translated material, BMJ does not warrant the accuracy and reliability of the translations (including but not limited to local regulations, clinical guidelines, terminology, drug names and drug dosages), and is not responsible for any error and/or omissions arising from translation and adaptation or otherwise.

Open access This is an open access article distributed in accordance with the Creative Commons Attribution Non Commercial (CC BY-NC 4.0) license, which permits others to distribute, remix, adapt, build upon this work non-commercially, and license their derivative works on different terms, provided the original work is properly cited, appropriate credit is given, any changes made indicated, and the use is non-commercial. See: http://creativecommons.org/licenses/by-nc/4.0/.

ORCID iD

Anam Shahil Feroz http://orcid.org/0000-0003-0180-0213

\section{REFERENCES}

1 Organization WH. Rolling updates on Covid.19, 2020. Available: https://www.who.int/emergencies/diseases/novel-coronavirus-2019/ events-as-they-happen

2 Organization WH. Who coronavirus disease (COVID-19) Dashboard, 2020. Available: https://covid19.who.int/

3 Corrigan P. On the Stigma of COVID-19. Let's separate the illness from the patient, 2020. Available: https://www.psychologytoday.com/ us/blog/the-stigma-effect/202004/the-stigma-covid-19

4 Saqlain M, Munir MM, Ahmed A, et al. Is Pakistan prepared to tackle the coronavirus epidemic? Drugs Ther Perspect 2020:213-4.

5 Akhtar H, Afridi M, Akhtar S, et al. Pakistan's response to COVID-19: overcoming national and international Hypes to fight the pandemic. JMIR Public Health Surveill 2021;7:e28517.

6 Waris A, Atta UK, Ali M, et al. COVID-19 outbreak: current scenario of Pakistan. New Microbes New Infect 2020;35:100681.

7 Javed B, Sarwer A, Soto EB, et al. Is Pakistan's response to coronavirus (SARS-CoV-2) adequate to prevent an outbreak? Front Med 2020;7:158.
8 UNICEF. WHO, IFRC. Social Stigma associated with COVID-19. A guide to preventing and addressing social stigma, 2020. Available: https://www epiwin com/sites/epiwin/files/content/ attachments/2020-02-24/COVID19\% 20Stigma\% 20Guide\% 2024022020_1 pdf adresinden erișilmiștir

9 Mahar I. Pakistan: Covid-19: rhetoric and reality, 2020. Available: http://southasiajournal.net/pakistan-covid-19-rhetoric-and-reality/

10 Gray N, Stringer B, Bark G, et al. 'When Ebola enters a home, a family, a community': a qualitative study of population perspectives on Ebola control measures in rural and urban areas of Sierra Leone. PLoS Negl Trop Dis 2018;12:e0006461.

11 Modarres N, Babalola S, Figueroa M. Community perspectives about Ebola in Bong, Lofa and Montserrado counties of Liberia: results of a qualitative study. Health Communication Capacity Collaborative, Johns Hopkins Center for Communication Programs \& USAID, 2015.

12 Kobayashi M, Beer KD, Bjork A, et al. Community Knowledge, Attitudes, and Practices Regarding Ebola Virus Disease - Five Counties, Liberia, September-October, 2014. MMWR Morb Mortal Wkly Rep 2015;64:714.

13 Teti M, Schatz E, Liebenberg L. Methods in the time of COVID-19: the vital role of qualitative inquiries. Los Angeles, CA: In: SAGE Publications Sage CA, 2020.

14 Saunders B, Sim J, Kingstone T, et al. Saturation in qualitative research: exploring its conceptualization and operationalization. Qual Quant 2018;52:1893-907.

15 Faulkner SL, Trotter SP, saturation D. The International encyclopedia of communication research methods, 2017: 1-2.

16 Hsieh H-F, Shannon SE. Three approaches to qualitative content analysis. Qual Health Res 2005;15:1277-88.

17 Abdelhafiz AS, Mohammed Z, Ibrahim ME, et al. Knowledge, Perceptions, and Attitude of Egyptians Towards the Novel Coronavirus Disease (COVID-19). J Community Health 2020;45:881-90.

18 Roy D, Tripathy S, Kar SK, et al. Study of knowledge, attitude, anxiety \& perceived mental healthcare need in Indian population during COVID-19 pandemic. Asian J Psychiatr 2020;51:102083.

19 Li L-Q, Huang T, Wang Y-Q, et al. COVID-19 patients' clinical characteristics, discharge rate, and fatality rate of meta-analysis. $J$ Med Virol 2020;92:577-83.

20 Liang W, Guan W, Chen R, et al. Cancer patients in SARSCoV-2 infection: a nationwide analysis in China. Lancet Oncol 2020;21:335-7.

21 Klemm C, Das E, Hartmann T. Swine flu and hype: a systematic review of media dramatization of the H1N1 influenza pandemic. $J$ Risk Res 2016;19:1-20.

22 Van Bavel JJ, Baicker K, Boggio PS. Using social and behavioural science to support COVID-19 pandemic response. Nature Human Behaviour 2020:1-12.

23 Andersen KG, Rambaut A, Lipkin WI, et al. The proximal origin of SARS-CoV-2. Nat Med 2020;26:450-2.

24 World Health Organization. Virtual press conference on COVID-19 in the Western Pacific. remarks by DR Takeshi Kasai, 2021. Available: https://www.who.int/westernpacific/news/speeches/detail/virtualpress-conference-on-covid-19-in-the-western-pacific

25 Dzigbede K, Gehl SB, Willoughby K. Disaster resiliency of U.S. local governments: insights to strengthen local response and recovery from the COVID-19 pandemic. Public Adm Rev 2020:641-3.

26 Government of Pakistan. COVID-19 Dashboard, 2021. Available: https://covid.gov.pk/stats/pakistan 